Reference : Merryweather G, Spearpoint M J. Ignition of New Zealand wood products in the LIFT, RIFT and ISO 5657 apparatus using the ASTM E 1321-97 protocol. Journal of Fire Sciences, Vol. 26, No. 1, pp. 63-88, 2008. http://dx.doi.org/10.1177/0734904107085381

\title{
IGNITION OF NEW ZEALAND WOOD PRODUCTS IN THE LIFT, RIFT AND ISO 5657 APPARATUS USING THE ASTM E 1321-97 PROTOCOL
}

\author{
G. Merryweather ${ }^{\mathrm{a}}$, M. J. Spearpoint ${ }^{\mathrm{b}, *}$ \\ a Lincolne Scott Ltd, Level 3, 65 Upper Queen Street, Auckland, 1001, New Zealand. \\ ${ }^{b}$ Department of Civil Engineering, University of Canterbury, Christchurch, 8020, New Zealand.
}

\begin{abstract}
The results from ignition tests conducted using the Lateral Ignition and Flame spread Test (LIFT) apparatus, Reduced scale Ignition and Flame spread Test (RIFT) apparatus and ISO 5657 ignitability apparatus from nine different types of New Zealand wood based products were used to obtain the critical ignition heat flux and thermal inertia using the procedure specified in ASTM E 1321-97a. It was found that vertically oriented samples in the LIFT and RIFT had a higher minimum ignition heat flux compared with the horizontal samples in the ISO 5657 apparatus. There was only a limited agreement between the three test methods for thermal inertia values.
\end{abstract}

KEYWORDS: Ignition, wood products, New Zealand wood species, fire test methods.

\footnotetext{
* corresponding author, michael.spearpoint@canterbury.ac.nz, tel: +64 3364 2237, fax: +64 33642758.
} 


$\begin{array}{lll}b & \text { Ignition parameter } & \mathrm{s} \\ c & \text { Specific heat } & \mathrm{J} \cdot \mathrm{kg}^{-1} \cdot \mathrm{K}^{-1} \\ h & \text { Heat transfer coefficient } & \mathrm{kW} \cdot \mathrm{m}^{-2} \cdot \mathrm{K}^{-1} \\ k & \text { Thermal conductivity } & \mathrm{kW} \cdot \mathrm{m}^{-1} \cdot \mathrm{K}^{-1} \\ \dot{q}^{\prime \prime} & \text { Heat flux } & \mathrm{kW} \cdot \mathrm{m}^{-2} \\ t & \text { Time } & \mathrm{s} \\ t^{*} & \text { Time for thermal equilibrium } & \mathrm{s} \\ T & \text { Temperature } & { }^{\circ} \mathrm{C}\end{array}$

Greek symbols

$\begin{array}{lll}\varepsilon & \text { Emissivity } & - \\ \rho & \text { Density } & \mathrm{kg} \cdot \mathrm{m}^{-3} \\ \sigma & \text { Stefan-Boltzmann constant } & 5.67 \times 10^{-8} \mathrm{kWm}^{-2} \cdot \mathrm{K}^{-4}\end{array}$

$\begin{array}{ll}\begin{array}{ll}\text { Subscripts } \\ \text { crit }\end{array} & \text { Critical ignition value } \\ \text { c } & \text { Convective } \\ e & \text { Incident on surface } \\ f & \text { Flame } \\ \text { ig } & \text { At ignition } \\ \text { min } & \text { Minimum value } \\ \text { surf } & \text { Surface } \\ x & \text { Measured at the } x \text { mm position on the sample } \\ \infty & \text { Ambient }\end{array}$

\section{INTRODUCTION}

The study of flame spread along the surface of materials is a key part to fire modelling and prediction of room fire growth [1]. The LIFT apparatus, which forms the basis of the lateral flame spread measurements in the ASTM E 1321-97a standard [2] has a footprint of approximately $1.7 \mathrm{~m}$ by $0.9 \mathrm{~m}$, and requires a fuel and compressed air supply for a radiant gas panel. The limited application of the LIFT and its bulkiness means that the number of LIFT testing facilities in the world is small. In comparison, the ASTM E 1354 cone calorimeter [3] is a commonly available apparatus that forms the basis of much of the recent research into 
material properties. The cone calorimeter has been shown to give good predictions of fire and test performance for materials and compartment flashover, however efforts to apply lateral flame spread using only cone calorimeter data have had limited success [4 - 6].

Research at FireSERT at the University of Ulster developed the Reduced scale Ignition and Flame spread (RIFT) apparatus [7, 8] which uses the cone calorimeter as the heat source for flame spread testing. Application of the theory developed by Quintiere et al. [9 - 11] gives the flame spread parameter not otherwise obtainable from cone calorimeter data. In previous research $[12,13]$ the RIFT results were compared with data previously published in the literature and not directly against LIFT data on material sourced from the same batch. This paper describes the ignition results obtained in our research in support of the flame spread testing which is described elsewhere [14].

\section{IGNITION}

\section{Background}

Since flame spread is essentially a piloted ignition process, its study depends on the ignition properties of the material being considered and there are a number of models for predicting ignition which are discussed in depth by Babrauskas $[15,16]$. Although there have been advances in the analysis of the ignition of wood materials, such as the work by Dietenberger [17], this research maintains the approach specified by ASTM E 1321-97a [2] so as to be consistent with previous work using the RIFT $[7,8,12,13]$ and because the results are used as input to flame spread experiments conducted according to ASTM E 1321-97a.

A material will ignite when a sufficient quantity has pyrolised to reach the lower flammable limit, and in the case of a piloted ignition, a suitable ignition source is available. The minimum heat flux for ignition $\left(\dot{q}_{i g, \min }^{\prime \prime}\right)$ is the lowest level at which the material will ignite within some time limit, and this varies depending on the requirements of a given test protocol. The value is found by a series of ignition tests and is the average of the highest flux level where there is no ignition and the lowest level that caused ignition. The critical ignition flux $\left(\dot{q}_{c r i t}^{\prime \prime}\right)$ is found by correlation, rather than as an experimental value, and different ignition theories can give different results. It is the theoretical lowest flux which will cause ignition given an infinitely long time. Implicit is that the material properties do not change significantly during that time. 


\section{Theory}

The ignition theory developed by Quintiere, Harkleroad and Walton [10] and further developed by Quintiere and Harkleroad [11] forms the basis for the ASTM E 1321 LIFT ignition tests and thus the material properties used in the flame spread part of the test. The theory uses an energy balance into a control volume for a semi-infinite one-dimensional slab. The material is modelled as an inert, grey body and it is assumed that the temperature increases under the received heat flux until it ignites at the ignition temperature. More generally, the sample is assumed to be "well behaved" with homogeneous properties, unaffected by the temperature increase to ignition, and the surface does not melt or blister.

A general approach to material ignition and flame spread is to assume ignition once the surface temperature ( $T_{\text {surf }}$ ) reaches the minimum temperature for piloted ignition $\left(T_{i g}\right)$, and this temperature increase is due to the external flux and any flame heat flux such that

$$
T_{\text {ig }}-T_{\text {surf }}=\Delta T_{e}+\Delta T_{f}
$$

and in the case of material ignition there is no flame present, thus $\Delta T_{f}=0$. Assuming the emissivity $\varepsilon=1$ as the surface chars before ignition, the heat flux to raise the temperature of the surface is

$$
\dot{q}_{e}^{\prime \prime}=h_{c}\left(T_{\text {surf }}-T_{\infty}\right)+\varepsilon \sigma\left(T_{\text {surf }}^{4}-T_{\infty}^{4}\right)
$$

and the minimum heat flux for ignition is

$$
\dot{q}_{i g, \min }^{\prime \prime}=h_{c}\left(T_{i g}-T_{\infty}\right)+\varepsilon \sigma\left(T_{i g}^{4}-T_{\infty}^{4}\right) \cong h\left(T_{i g}-T_{\infty}\right)
$$

The surface temperature required for ignition can be calculated from Equation (3) if $h$ is known. Quintiere et al. [10] obtained Equations (4) to (6) for the surface temperature, where the absorptivity is assumed to be equal to 1 and $\dot{q}_{e, x_{f}}^{\prime \prime}$ is the heat flux at position $x$ along a sample, thus

$$
\Delta T_{e}=T_{\text {surf }}-T_{\infty}=\dot{q}_{e, x_{f}}^{\prime \prime}[1-\exp (a t) \operatorname{erfc} \sqrt{a t}] / h
$$

where $a=\frac{h^{2}}{k \rho c}$ or

$$
\Delta T_{e}=T_{\text {surf }}-T_{\infty}=\dot{q}_{e, x f}^{\prime \prime} F(t) / h
$$

and where $F(t)$ is the time transient term

$$
F(t)=1-\exp (a t) \operatorname{erfc} \sqrt{a t} .
$$


As the time the sample is exposed to the external flux increases, then $F(t)$ tends to zero as the material surface approaches equilibrium. From ignition tests [18] $F(t)$ is related to the flux levels as

$$
\frac{\dot{q}_{i g, \min }^{\prime \prime}}{\dot{q}_{e}^{\prime \prime}}=F(t)=\left\{\begin{array}{cc}
b \sqrt{t} & t \leq t^{*} \\
1 & t \geq t^{*}
\end{array}\right.
$$

where $t^{*}$ is the preheating time to reach thermal equilibrium. As the time $t$ increases then $F(t)$ tends to a value of 1 at long ignition times. At high heat fluxes, time $t \rightarrow 0$ and the exponential term tends to a value of 1 and as a result $F(t)$ tends to a function dependent on the thermal inertia so that

$$
F(t)=1-\exp (a t) \operatorname{erfc} \sqrt{(a t)} \rightarrow \frac{2 h \sqrt{t}}{\sqrt{\pi k \rho c}} \text { as } t \rightarrow 0
$$

Hence for the period of time when $t$ is small, then $F(t)$ can also be written as

$$
F(t)=\frac{2 h}{\sqrt{\pi k \rho c}} \sqrt{t} \text { as } t \rightarrow 0 \quad \text { or } \quad F(t)=b \sqrt{t}
$$

where $b$ is the 'ignition parameter' given in Equation (10) and can be used to obtain the effective thermal inertia $k \rho c$ as

$$
b=\frac{2 h}{\sqrt{\pi k \rho c}} \text { or } k \rho c=\frac{4}{\pi}\left(\frac{h}{b}\right)^{2}
$$

\section{Data Analysis}

The ignition theory can be applied to laboratory tests to obtain material parameters relevant to ignition and flame spread according to ASTM E 1321. The minimum heat flux for ignition $\left(\dot{q}_{i g, \min }^{\prime \prime}\right)$ is given by plotting the time to ignition $\left(t_{i g}\right)$ versus incident heat flux $\left(\dot{q}_{e}^{\prime \prime}\right)$ and the curve will asymptote at the value for $\dot{q}_{i g, \min }^{\prime \prime}$. Plotting the incident heat flux $\left(\dot{q}_{e}^{\prime \prime}\right)$ versus $1 / \sqrt{ }\left(t_{i g}\right)$ gives the critical heat flux $\left(\dot{q}_{c r i t}^{\prime \prime}\right)$ from the intercept with the x-axis. In this work, the ignition temperature $\left(T_{i g}\right)$ is obtained from FIG. 10 of the ASTM E1321-97a and hence $h$ can then be determined from Equation (3).

Using the protocol from ASTM E 1321-97a, $\left(\dot{q}_{i g, \min }^{\prime \prime} / \dot{q}_{e}^{\prime \prime}\right)$ is plotted versus $\sqrt{ }\left(t_{i g}\right)$. The intercept of a best fit line with $\left(\dot{q}_{i g \text {,min }}^{\prime \prime} / \dot{q}_{e}^{\prime \prime}\right)=1$ gives the square root of the preheating time $\sqrt{ } t^{*}$ and the slope of $\left(\dot{q}_{i g, \min }^{\prime \prime} / \dot{q}_{e}^{\prime \prime}\right)$ versus $\sqrt{ }\left(t_{i g}\right)$ is the ignition parameter $(b)$. The ignition parameter can then be used to solve for the thermal inertia $(k \rho c)$ using Equation (10). 
Since the behaviour of the material changes as the heating time increases, the fit of the data for the correlation to a straight line becomes increasingly less reliable due to scatter in the data, in particular for the data used in Quintiere et al's method. The values which best reflect the thermal inertia are those at the higher heat fluxes with the correspondingly shorter ignition times. For the most accurate result, some of the data points close to the minimum ignition flux must be ignored. The choice of acceptable data points is not clearly defined, a problem that has occurred for other researchers [19]. In this paper, attempting to define the limit based on the thermal penetration depth did not give a definite cut-off for acceptable data, especially if there was some scatter. In order to provide consistency, the data was plotted and a regression fitted to the data was visually inspected. As a guide, points above $\left(\dot{q}_{i g, \min }^{\prime \prime} / \dot{q}_{e}^{\prime \prime}\right)>0.8$ were discarded if that significantly improved the fit of the data. This value was chosen as it encompassed the values close to the minimum ignition flux where the deviation was the greatest. The $\mathrm{R}^{2}$ correlation coefficient calculated for the fit of the data was used as a guide to what was deemed a "significant" difference. When considering whether to include a data point, it was somewhat arbitrary, but if the $\mathrm{R}^{2}$ value improved by more than 0.15 by excluding a data point, then this was deemed to be significant, and the value could be deleted. The difference was generally obvious from visual inspection. It should be noted that the choice of which data points to include can have a significant effect on the ignition parameter $(b)$ and particularly the preheating time $t^{*}$ used in the subsequent flame spread tests conducted by Merryweather [14].

\section{TEST METHODS}

\section{The Lateral Ignition and Flame spread Test (LIFT) Apparatus}

The ASTM E 1321 standards series [2] was a development of the ASTM E 1317 Standard for marine surface finishes [20] and work by Quintiere et al. [9 - 11]. The ASTM E1321-97a LIFT testing apparatus uses a gas fuelled diffusion burner and a vertical sample holder. The $155 \mathrm{~mm}$ by $800 \mathrm{~mm}$ sample holder is angled at $15^{\circ} \pm 0.25^{\circ}$ to the face of the burner. The burner offset can be adjusted to give the best match to the standard flux profile. This gives an almost constant flux level for the first $150 \mathrm{~mm}$ along the sample for use in ignition testing, and then a decreasing flux level to approximately $2 \%$ of the peak heat flux. The burner is a flat panel burner $280 \mathrm{~mm}$ high by $430 \mathrm{~mm}$ long with radiant ceramic elements and a reverberant screen. The fuel used in the burner in the original research [9] and the subsequent ASTM standard is methane which gives a wide range incident heat fluxes for the ignition test procedure.

The LIFT test procedure comprises of two parts, the first is an ignition test where the time to piloted ignition $t_{i g}$ of $155 \times 155(+0,-5)$ mm samples is obtained for various incident heat fluxes 
and the minimum heat flux for ignition is obtained by bracketing to find the lowest flux which will cause ignition within 20 minutes. The critical heat flux, thermal equilibrium and ignition parameter are obtained from the analysis procedure described earlier.

The LIFT apparatus used in these experiments followed the design for the ASTM E 1317 apparatus with the modifications listed for the ASTM E 1321-97a standard. However whereas the ASTM E 1321-97a standard calls for methane powered radiant panel with an air-acetylene ignition pilot flame, the LIFT employed in this work used a Liquefied Petroleum Gas (LPG) and compressed air mixture for the radiant panel and ignition pilot due to the unavailability of a suitable source of methane. LPG is a mixture of propane and butane, and propane has been used for ignition experiments with the ASTM E 1623 ICAL intermediate scale calorimeter [21], which also normally runs on methane or natural gas. Similarly, in a round robin test described by Pauner [22] it was noted that one of the laboratories used propane for the radiant panel burner, although this was later changed to methane.

The heat flux level at the sample face was measured using a water cooled heat flux gauge mounted in a measuring template and fitted to a sample holder frame. The flux measurements for the ignition tests were conducted at $50 \mathrm{~mm}$ from the edge of the flange on the front face of the sample holder frame. The propane burner had a lower limit of $\dot{q}_{50 m m}^{\prime \prime}=20-25 \mathrm{~kW} \cdot \mathrm{m}^{-2}$ when set up in accordance to the standard LIFT spacing as the burner behaviour became unstable and had uneven heating below this level. This was not a limitation for the later flame spread tests as the flux level is usually set to $5-10 \mathrm{~kW} \cdot \mathrm{m}^{-2}$ over the minimum ignition flux. For timber based products the minimum ignition flux is usually in the order of $12 \mathrm{~kW} \cdot \mathrm{m}^{-2}$ [15], and usually higher for ignition tests conducted in the LIFT [16]. An upper limit was found of $\dot{q}_{50 \mathrm{~mm}}^{\prime \prime}=50 \mathrm{~kW} \cdot \mathrm{m}^{-2}$, due to the air supply to the burner although this could be raised to greater than $60 \mathrm{~kW} \cdot \mathrm{m}^{-2}$ using an additional air compressor in parallel with the main air supply. For ignition tests the LIFT apparatus used in this work was modified so that the spacing of the radiant panel could be adjusted on slide on rails to give the lower flux levels within the limitations of the burner output.

Samples were conditioned at $50 \pm 5 \% \mathrm{RH}$ and $23 \pm 3^{\circ} \mathrm{C}$ for at least two weeks so that successive weight measurements taken 24 hours apart did not vary by more than $0.1 \%$ of the mass. Each sample was wrapped with foil on the back and sides and placed with an insulated backing board in a second sample holder. Tests was done at varying heat flux levels to bracket the minimum flux for ignition to within $2 \mathrm{~kW} \cdot \mathrm{m}^{-2}$, as called for by ASTM E 1321-97a, and up to the maximum that the burner could deliver. 


\section{The ISO 5657-1987 Ignition Apparatus}

The ISO 5657-1987 ignition apparatus is similar to the cone calorimeter, in that it uses a conical electrical element with a maximum heat flux to the sample of $50 \mathrm{~kW} \cdot \mathrm{m}^{-2}$. The standard test uses a small pilot flame, which is dipped above the sample at $4 \mathrm{~s}$ intervals giving a resolution of $\pm 2 \mathrm{~s}$. Babrauskas [16] notes that the original version of the apparatus had provision for both the gas and electric spark ignition systems and the apparatus used for this research used a spark ignition which is a deviation from the ISO 5657 standard. The test apparatus uses a weighted platform with a counterweight to hold a $165 \mathrm{~mm}$ square sample against a flat plate in order to provide a consistent distance from the sample to the element, even if the top of the sample shrinks away. Only a circular area of $150 \mathrm{~mm}$ diameter of the sample is exposed to the element, with the remainder of the sample shielded by the flat plate. A shield is used while the sample is being placed in position which is removed and timing started until the sample ignites, or the test duration is over.

\section{Reduced scale Ignition and Flame spread Test (RIFT) Method}

The RIFT method is a result of research by Azhakesan et al. [7, 8] where the objective was to provide an alternative to the standard LIFT test for spread-of-flame measurements by using a modified cone calorimeter. Following on from Azhakesan et al., further work has been carried out by Pease [12] and Huynh [13]. The cone calorimeter element is set to the vertical position and the long axis centreline of the RIFT sample holder inline with the centreline of the cone. The end of the sample closest to the element is positioned in line with the edge of the element (Figure 1). The sample separation distance of $45 \mathrm{~mm}$ is set by measuring perpendicularly from the face of the cone to the sample and an angle of 60 degrees to the cone heater element face has found to be appropriate $[7,12,13,14]$. 


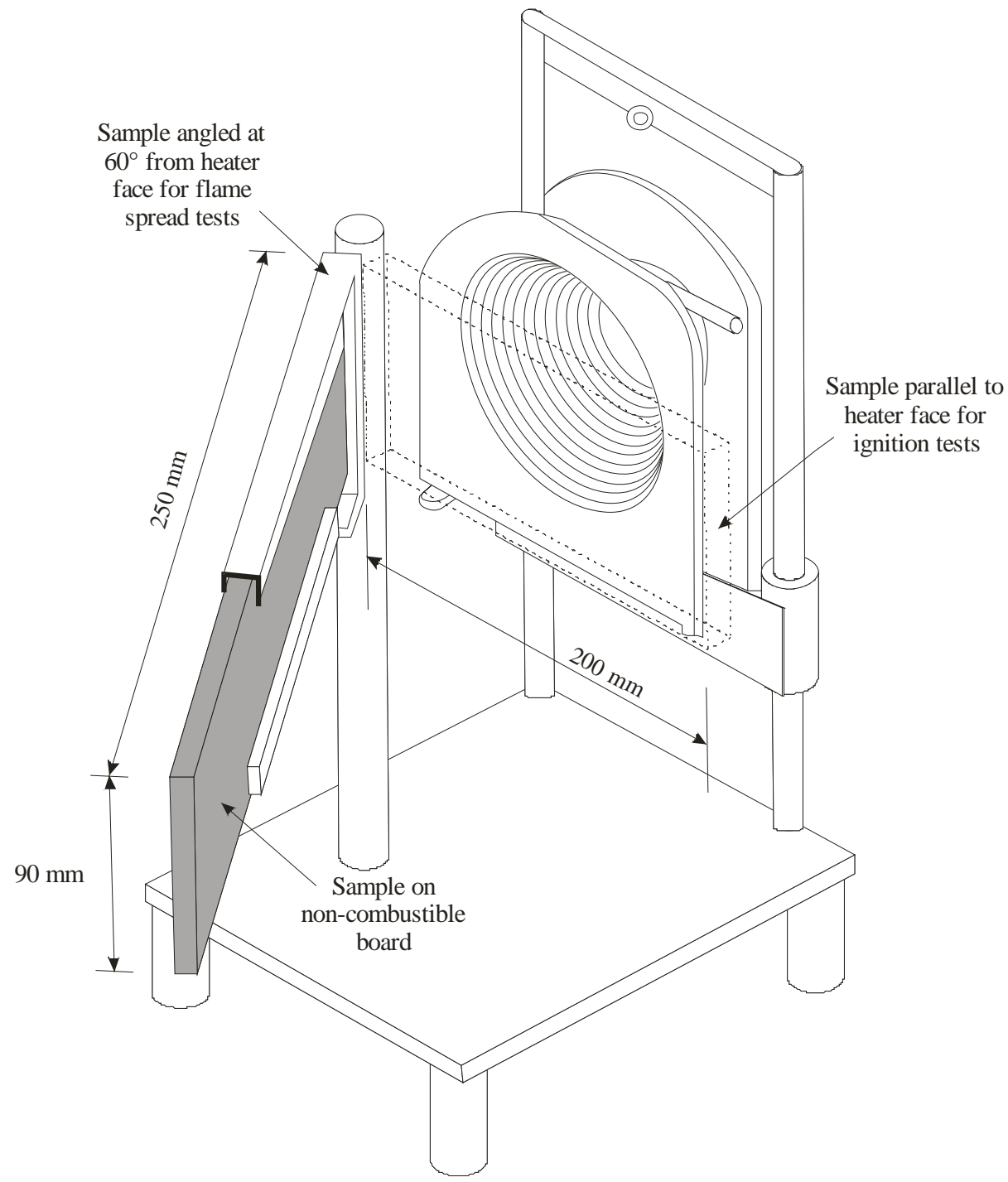

Figure 1. RIFT apparatus for ignition and flame spread testing - adapted from Azhakesan et al. [7].

Previous studies involving the RIFT used either the cone calorimeter in the normal horizontal position [7, 13], or results from the ISO 5657 apparatus [13] to obtain the ignition data. In this research ignition tests were conducted using the RIFT as a comparison with the ISO 5657 apparatus. The RIFT ignition test used $200 \mathrm{~mm}$ x $95 \mathrm{~mm}$ samples mounted parallel to the cone element (Figure 1), and exposed to a constant heat flux. The spark igniter was level with the top of the exposed face of the sample, and $13 \mathrm{~mm}$ from the sample face. The heat flux at the mid point of the cone was adjusted over a series of ignition tests so that ignition did not occur before $20 \mathrm{~min}$. The sample conditioning and ignition testing procedures for using the RIFT apparatus were based on the ASTM E1321-97a LIFT standard. The rear and sides of the samples were wrapped in aluminium foil and a $12 \mathrm{~mm}$ thick insulating board used behind the sample. 


\section{Influence of Sample Characteristics and Test Method}

Since each of the tests methods differ in their specific design characteristics it is likely that sample orientation, size and thickness will affect the ignition times obtained [16]. The LIFT ignition test uses a sample that is held in the vertical plane, whereas the conventional cone calorimeter and ISO 5657 apparatus uses a sample in the horizontal orientation. Dietenberger [23] found that the time to ignition for samples in the cone calorimeter with a horizontal sample was less than that for the LIFT. Similarly, ignition times are longer for samples in the cone calorimeter in the vertical position against the same materials measured in the horizontal position [16]. Shields, Silcock and Murray [24] did extensive work on the ISO 5657 ignition apparatus and compared the results to the cone calorimeter allowing for the margin of error due to the interval of the nodding gas pilot. The cone calorimeter and ISO apparatus gave similar ignition times for heat fluxes between $40-70 \mathrm{~kW} \cdot \mathrm{m}^{-2}$, however at lower flux levels (down to

$20 \mathrm{~kW} . \mathrm{m}^{-2}$ ) times to ignition were significantly influenced by specimen orientation for the different modes of ignition. It was therefore expected in this research that the RIFT would have longer ignition times than the ISO 5657 apparatus, due to the orientation, in the same manner as the LIFT.

The size of the sample can have an effect on the time to ignition, particularly in the vertical orientation. The main difference as the sample height increases is the thickening of the boundary layer and hence the convection coefficient [16]. The thickness of the material affects the time to ignition due to the heat loss through the rear of the sample. While materials over $1 \mathrm{~mm}$ in thickness are generally thermally thick or thermally indeterminate, it depends on the flux level and preheating time [16]. The ignition and flame spread theory for the LIFT standard is based on materials being thermally thick so the thickness of the materials should be chosen appropriately. The ASTM E 1321-97a standard notes that materials in this category are typically $2-5 \mathrm{~mm}$ thick, and where the material is less than this, the results apply to the facing and substrate combination as the substrate can have a significant effect on the ignition and flame spread results.

\section{EXPERIMENTS AND RESULTS}

\section{Procedure}

Nine general types of wood based materials were used (Table 1) with some limited tests conducted on variations of these materials. The materials chosen for the tests in this work were based on the availability of previously published data, particularly Huynh [13], Azhakesan et al. 
[7] and also Ngu [26]. The moisture content of the conditioned materials were determined by oven drying and although the moisture content has a systematic effect on ignition time, as Dietenberger [23] shows for example, Babrauskas [15] notes that changes in moisture content of timber at room equilibrium do not make a significant difference to ignition times and that differences for moisture contents between $0-12 \% \mathrm{MC}$ is lost in the data scatter.

\begin{tabular}{|c|c|c|c|c|c|}
\hline Material & $\begin{array}{l}\text { Manufacturer } \\
\text { and trade name }\end{array}$ & Description & $\begin{array}{c}\text { Thickness* } \\
(\mathrm{mm})\end{array}$ & $\begin{array}{l}\text { Density } \\
\left(\mathrm{kg} \cdot \mathrm{m}^{-3}\right)\end{array}$ & $\begin{array}{c}\text { Moisture } \\
\text { content } \\
(\%)\end{array}$ \\
\hline hardboard & unbranded & $\begin{array}{l}\text { hardboard } \\
\text { fibreboard }\end{array}$ & 5 & 819 & 6.3 \\
\hline plywood & IPL “Tuffply” & $\begin{array}{l}\text { C/D grade } \\
\text { untreated Radiata } \\
\text { Pine }\end{array}$ & 17 & 487 & 7.8 \\
\hline $\begin{array}{l}\text { particle board } \\
\text { (chipboard) }\end{array}$ & 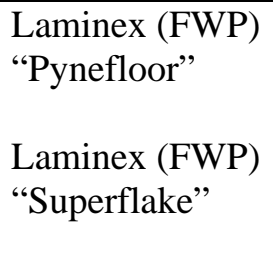 & $\begin{array}{l}\text { Radiata Pine based } \\
\text { flooring particle } \\
\text { board } \\
\text { Radiata Pine based } \\
\text { particle board }\end{array}$ & 20 & 745 & 8.0 \\
\hline $\begin{array}{l}\text { medium density } \\
\text { fibreboard } \\
\text { (MDF) }\end{array}$ & $\begin{array}{l}\text { FWP } \\
\text { "Customwood" }\end{array}$ & $\begin{array}{l}\text { Radiata Pine based } \\
\text { standard MDF }\end{array}$ & 18 & 620 & 7.1 \\
\hline $\begin{array}{l}\text { Melteca faced } \\
\text { MDF }\end{array}$ & $\begin{array}{l}\text { Laminex (FWP) } \\
\text { Melteca }\end{array}$ & $\begin{array}{l}\text { white Melamine } \\
\text { faced MDF }\end{array}$ & 18 & 681 & 8.2 \\
\hline $\begin{array}{l}\text { Melteca faced } \\
\text { particle board }\end{array}$ & $\begin{array}{l}\text { "Regal”, from } \\
\text { builders } \\
\text { merchant }\end{array}$ & $\begin{array}{l}\text { white Melamine } \\
\text { pre - finished } \\
\text { shelving }\end{array}$ & 18 & 661 & $\mathrm{n} / \mathrm{a}$ \\
\hline Radiata Pine & - & $\begin{array}{l}\text { clear grade, kiln } \\
\text { dried and untreated }\end{array}$ & $16 / 20$ & 425 & 9.5 \\
\hline Macrocarpa & - & clear grade & $16 / 20$ & 514 & 8.6 \\
\hline Rimu & - & $\begin{array}{l}\text { New Zealand, heart } \\
\text { grade }\end{array}$ & $16 / 20$ & 660 & 10.4 \\
\hline Beech & - & New Zealand & $16 / 22$ & 489 & 9.7 \\
\hline
\end{tabular}

* RIFT / LIFT \& ISO 5657

$\mathrm{n} / \mathrm{a}$ - not recorded

Table 1. Wood based materials tested.

Ignition tests for each material were conducted at different heat fluxes in the ISO 5657 apparatus, the LIFT and the RIFT to obtain the material properties required for flame spread tests. Due to the limited amount of material available for all of the ignition and flame spread experiments only a single ignition test for each combination of flux level and apparatus was conducted. As noted in Table 1, the thickness of the natural timbers used in the RIFT was less 
than the samples used in the LIFT due to difficulties in inserting the thicker samples into the sample holder.

It was noted that in several cases the analysis of the data resulted in a negative critical heat flux for a material in a particular test apparatus. Clearly a negative value has no physical meaning. If the materials behaved as thermally thin solids at low heat fluxes, as noted by de Ris and Kahn [25], then ignition times are shorter than if the material behaves as a thermally thick solid and consequently it pulls the regression upwards so that the intercept becomes very small or negative.

\section{Plain Manufactured Boards}

MDF showed very consistent ignition times in the three tests methods. Figure 2a shows that these results are within the error limits of the times obtained by Ngu [26] in the ISO 5657 apparatus. Results for the critical ignition flux for MDF are shown in Figure 3e. The RIFT intercept was found to be negative whereas values from the LIFT and ISO 5657 gave similar values of $3.4 \mathrm{~kW} \cdot \mathrm{m}^{-2}$ and $3.7 \mathrm{~kW} \cdot \mathrm{m}^{-2}$ respectively.

Results for the critical ignition flux for hardboard are shown in Figure 3a. Values from the LIFT and RIFT gave similar values of $2.2 \mathrm{~kW} \cdot \mathrm{m}^{-2}$ and $2.6 \mathrm{~kW} \cdot \mathrm{m}^{-2}$ respectively whereas the ISO 5657 intercept resulted in a negative value. The hardboard sample in the ISO 5657 apparatus was backed with $20 \mathrm{~mm}$ lightweight low density insulating board and the RIFT ignition test used 12 mm lightweight board. In all of the LIFT experiments a calcium silicate board with a density of $1240 \mathrm{~kg} / \mathrm{m}^{3}$ was used which deviated from the $200 \pm 50 \mathrm{~kg} / \mathrm{m}^{3}$ ASTM E 1231 requirement. This may have affected the ignition time comparison, as the hardboard was physically thin in comparison to the other materials tested, however Quintiere and Harkleroad [11] found little difference attributable to the density of the backing board. 


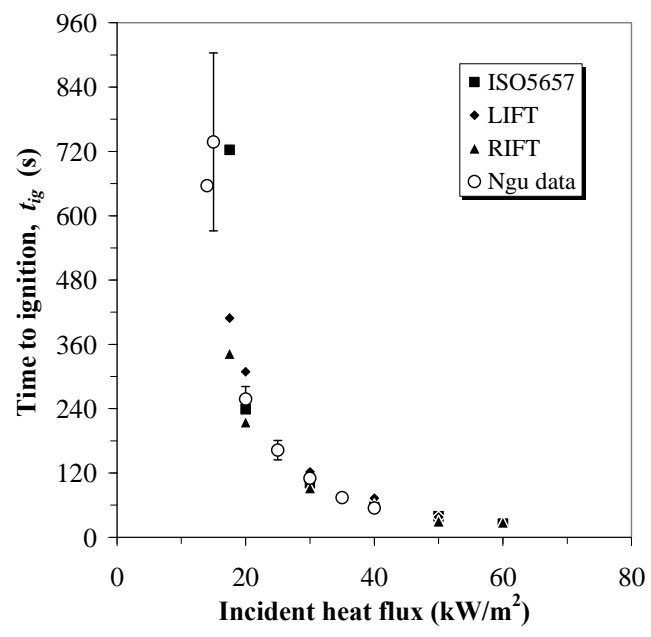

(a)

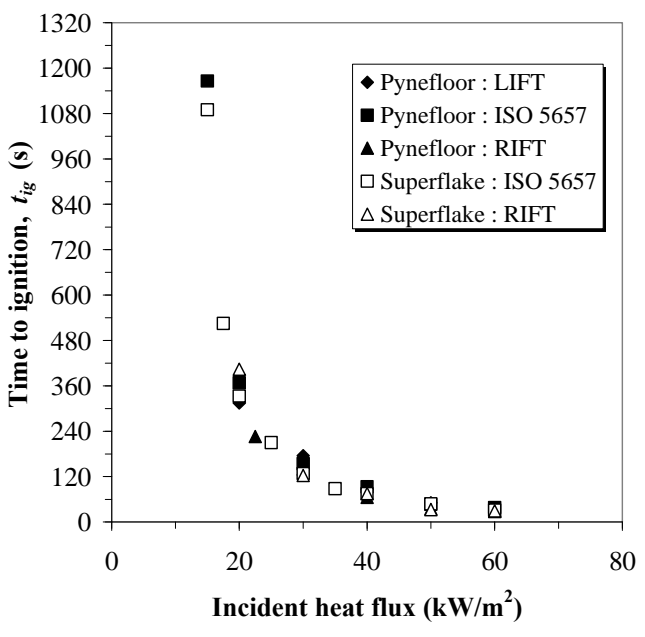

(b)

Figure 2. Time to ignition versus incident heat flux: (a) MDF; (b) Pynefloor and Superflake particle board.

Two brands of Radiata Pine based particle board, made by the Laminex division of Fletcher Wood Panels (FWP), were tested with the 'Pynefloor' having a higher density than the 'Superflake' board. The Pynefloor uses a polymerised urea formaldehyde adhesive (up to 15\% of the board content), to give weather resistance, whereas Superflake uses a melamine urea formaldehyde adhesive (up to $13 \%$ of the board content), and is for internal use only. The ignition times for the two brands of particle board are shown in Figure 2b. Overall the results are comparable with the small difference in the ISO 5657 apparatus appears to be approximately in proportion to the product density, where the higher density material (Pynefloor) has a longer time to ignition at any given heat flux level. The results of the ignition tests for Pynefloor particle board gave the minimum flux for ignition as $13.75 \mathrm{~kW} / \mathrm{m}^{2}$ for the ISO 5657 apparatus ignition tests whereas the LIFT and RIFT gave higher values for the minimum ignition flux (18.75 kW. $\mathrm{m}^{-2}$ and $21.25 \mathrm{~kW} . \mathrm{m}^{-2}$ respectively). The results for Superflake particle board were similar. The critical ignition flux for the two brands of particle board (Figure 3b and Figure 3c) gave similar results.

Plywood is made from layers of wood, with the grain direction of each ply at $90^{\circ}$ to the neighbouring plies, and joined with a pressure cured adhesive. A C/D grade plywood was used in this study where the $\mathrm{D}$ grade face is rough and empty knots are allowed. The $\mathrm{C}$ grade face is sanded and surface knots are secure or filled and this face was used for the ignition tests. The 
critical ignition flux (Figure 3d) given by the three ignition methods gave a range of results from $4.6 \mathrm{~kW} \cdot \mathrm{m}^{-2}$ to $9.9 \mathrm{~kW} \cdot \mathrm{m}^{-2}$. It was noted in the ISO 5657 apparatus experiments that the sample exhibited considerable charring and a glowing spot before finally igniting after over $28 \mathrm{~min}$ at an incident heat flux of $12.5 \mathrm{~kW} \cdot \mathrm{m}^{-2}$.

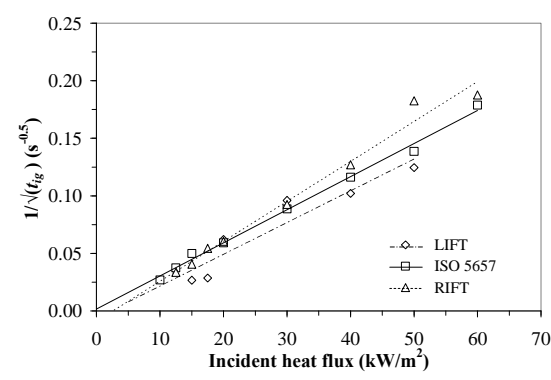

(a)

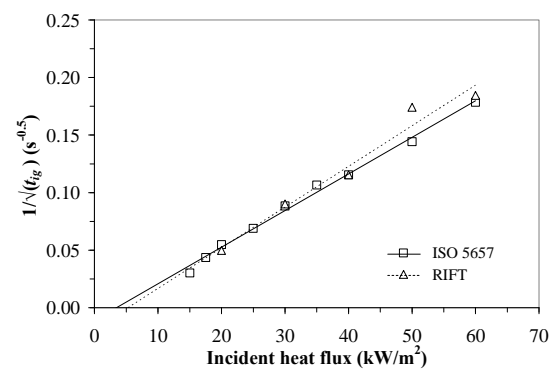

(c)

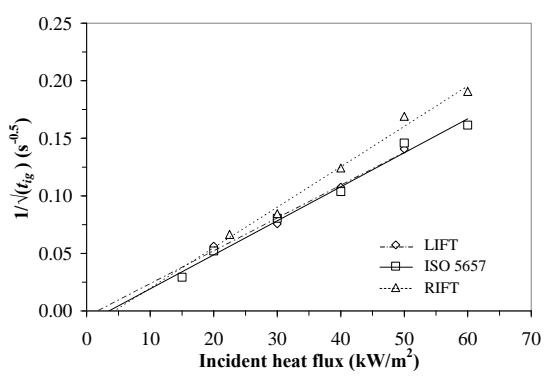

(b)

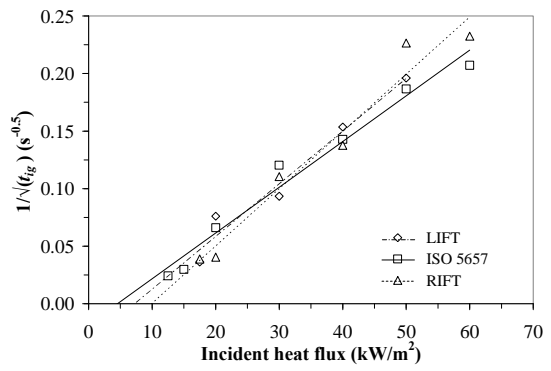

(d)

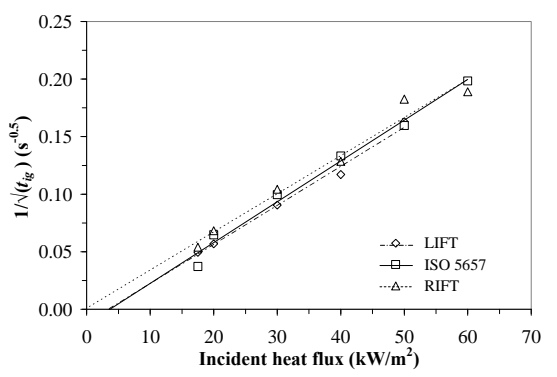

(e)

Figure 3. Determination of critical heat flux for plain manufactured timber products: (a) hardboard; (b) Pynefloor particle board; (c) Superflake particle board; (d) plywood; (e) medium density fibreboard.

Figure 4 shows the determination of the ignition parameter for the plain manufactured timber products. The ignition parameter for hardboard shows considerable spread between the LIFT and ISO 5657 apparatus ignition results. The ignition test conducted in the ISO 5657 apparatus gave a preheating time of $1195 \mathrm{~s}$, compared with the LIFT calculated preheating time of $608 \mathrm{~s}$. Plywood shows less spread in the results compared with the particle board, largely due to the 
minimum ignition flux being similar for all three test methods. Table 2 gives a summary of ignition properties obtained for the three test methods for the plain manufactured boards.

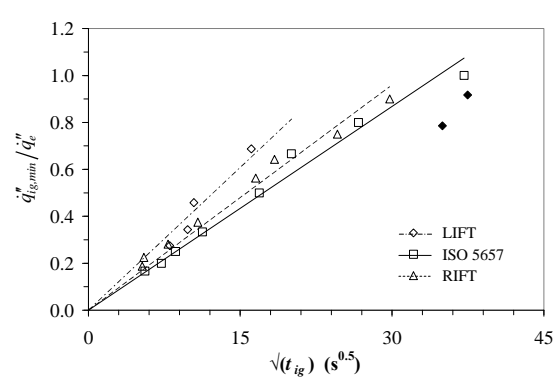

(a)

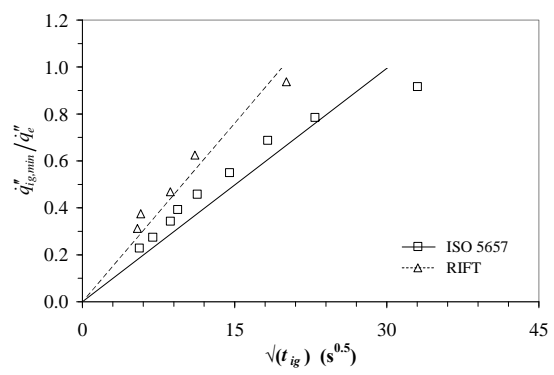

(c)

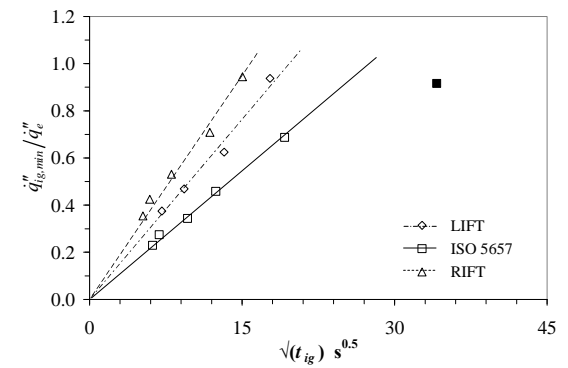

(b)

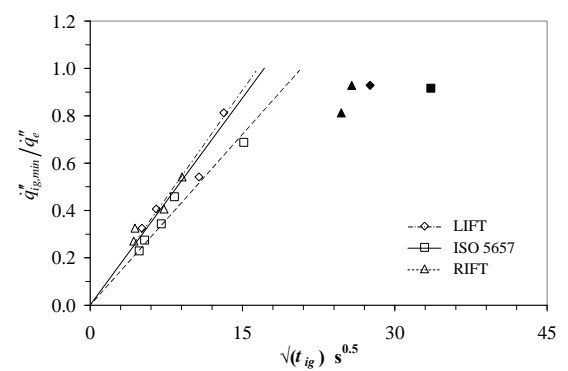

(d)

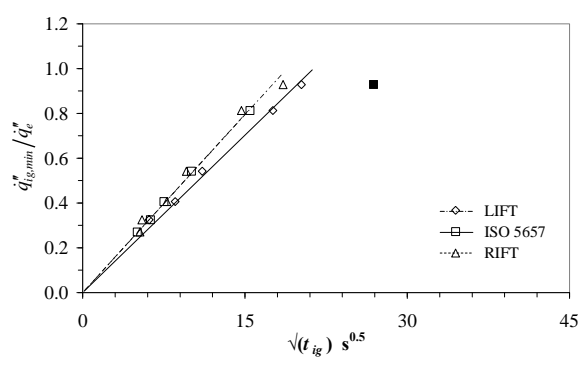

(e)

Figure 4. Determination of ignition parameter for plain manufactured timber products: (a) hardboard; (b) Pynefloor particle board; (c) Superflake particle board; (d) plywood; (e) medium density fibreboard. Data excluded from determination of ignition parameter are shown as solid symbols. 


\begin{tabular}{|c|c|c|c|c|}
\hline Product & Property & LIFT & ISO 5657 & RIFT \\
\hline \multirow{7}{*}{ 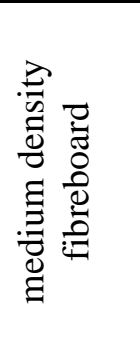 } & Ignition parameter, $b\left[\mathrm{~s}^{0.5}\right]$ & 0.047 & 0.053 & 0.053 \\
\hline & Preheat time, $t^{*}[\mathrm{~s}]$ & 456 & 355 & 357 \\
\hline & Critical ignition flux, $\dot{q}_{c r i t}^{\prime \prime}\left[\mathrm{kW} \cdot \mathrm{m}^{-2}\right]$ & 3.4 & 3.7 & -0.3 \\
\hline & Thermal inertia, $k \rho c\left[\mathrm{~kJ}^{2} \cdot \mathrm{m}^{-4} \cdot \mathrm{K}^{-2} \cdot \mathrm{s}^{-1}\right]$ & 1.10 & 0.86 & 0.86 \\
\hline & Min. ignition flux, $\dot{q}_{i g, \min }^{\prime \prime}\left[\mathrm{kW} \cdot \mathrm{m}^{-2}\right]$ & 16.25 & 16.25 & 16.25 \\
\hline & Heat transfer coefficient, $h\left[\mathrm{~kW} \cdot \mathrm{m}^{-2} . \mathrm{K}\right]$ & 0.044 & 0.044 & 0.043 \\
\hline & Ignition temperature, $T_{i g}\left[{ }^{\circ} \mathrm{C}\right]$ & 391 & 391 & 391 \\
\hline \multirow{7}{*}{$\begin{array}{l}\bar{D} \\
8 \\
3 \\
\frac{3}{2}\end{array}$} & Ignition parameter, $b\left[\mathrm{~s}^{0.5}\right]$ & 0.058 & 0.048 & 0.061 \\
\hline & Preheat time, $t^{*}[\mathrm{~s}]$ & 293 & 432 & 273 \\
\hline & Critical ignition flux, $\dot{q}_{c r i t}^{\prime \prime}\left[\mathrm{kW} \cdot \mathrm{m}^{-2}\right]$ & 7.2 & 4.6 & 9.9 \\
\hline & Thermal inertia, $k \rho c\left[\mathrm{~kJ}^{2} \cdot \mathrm{m}^{-4} \cdot \mathrm{K}^{-2} \cdot \mathrm{s}^{-1}\right]$ & 0.71 & 0.93 & 0.66 \\
\hline & Min. ignition flux, $\dot{q}_{i g, \min }^{\prime \prime}\left[\mathrm{kW} \cdot \mathrm{m}^{-2}\right]$ & 16.3 & 13.8 & 16.3 \\
\hline & Heat transfer coefficient, $h\left[\mathrm{~kW} \cdot \mathrm{m}^{-2} . \mathrm{K}\right]$ & 0.044 & 0.041 & 0.043 \\
\hline & Ignition temperature, $T_{i g}\left[{ }^{\circ} \mathrm{C}\right]$ & 391 & 352 & 391 \\
\hline \multirow{7}{*}{ 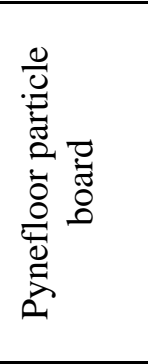 } & Ignition parameter, $b\left[\mathrm{~s}^{0.5}\right]$ & 0.051 & 0.036 & 0.063 \\
\hline & Preheat time, $t^{*}[\mathrm{~s}]$ & 386 & 755 & 250 \\
\hline & Critical ignition flux, $\dot{q}_{c r i t}^{\prime \prime}\left[\mathrm{kW} \cdot \mathrm{m}^{-2}\right]$ & 1.7 & 3.5 & 4.3 \\
\hline & Thermal inertia, $k \rho c\left[\mathrm{~kJ}^{2} \cdot \mathrm{m}^{-4} \cdot \mathrm{K}^{-2} \cdot \mathrm{s}^{-1}\right]$ & 0.96 & 1.64 & 0.70 \\
\hline & Min. ignition flux, $\dot{q}_{i g, \min }^{\prime \prime}\left[\mathrm{kW} \cdot \mathrm{m}^{-2}\right]$ & 18.75 & 13.75 & 21.25 \\
\hline & Heat transfer coefficient, $h\left[\mathrm{~kW} \cdot \mathrm{m}^{-2} . \mathrm{K}\right]$ & 0.044 & 0.041 & 0.047 \\
\hline & Ignition temperature, $T_{i q}\left[{ }^{\circ} \mathrm{C}\right]$ & 425 & 352 & 454 \\
\hline \multirow{7}{*}{ 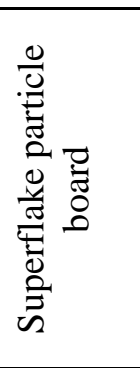 } & Ignition parameter, $b\left[\mathrm{~s}^{0.5}\right]$ & \multirow{7}{*}{ 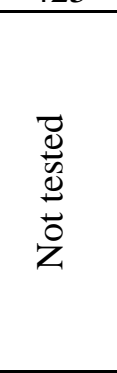 } & 0.033 & 0.051 \\
\hline & Preheat time, $t^{*}[\mathrm{~s}]$ & & 910 & 389 \\
\hline & Critical ignition flux, $\dot{q}_{c r i t}^{\prime \prime}\left[\mathrm{kW} \cdot \mathrm{m}^{-2}\right]$ & & 3.4 & 5.2 \\
\hline & Thermal inertia, $k \rho c\left[\mathrm{~kJ}^{2} \cdot \mathrm{m}^{-4} \cdot \mathrm{K}^{-2} \cdot \mathrm{s}^{-1}\right]$ & & 2.05 & 1.05 \\
\hline & Min. ignition flux, $\dot{q}_{i g, \min }^{\prime \prime}\left[\mathrm{kW} \cdot \mathrm{m}^{-2}\right]$ & & 13.75 & 18.75 \\
\hline & Heat transfer coefficient, $h\left[\mathrm{~kW} \cdot \mathrm{m}^{-2} . \mathrm{K}\right]$ & & 0.042 & 0.046 \\
\hline & Ignition temperature, $T_{i g}\left[{ }^{\circ} \mathrm{C}\right]$ & & 352 & 425 \\
\hline \multirow{7}{*}{ 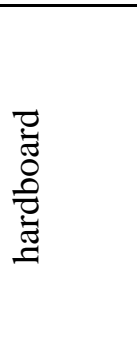 } & Ignition parameter, $b\left[\mathrm{~s}^{0.5}\right]$ & 0.041 & 0.029 & 0.032 \\
\hline & Preheat time, $t^{*}[\mathrm{~s}]$ & 608 & 1195 & 977 \\
\hline & Critical ignition flux, $\dot{q}_{c r i t}^{\prime \prime}\left[\mathrm{kW} \cdot \mathrm{m}^{-2}\right]$ & 2.2 & -0.6 & 2.6 \\
\hline & Thermal inertia, $k \rho c\left[\mathrm{~kJ}^{2} \cdot \mathrm{m}^{-4} \cdot \mathrm{K}^{-2} \cdot \mathrm{s}^{-1}\right]$ & 1.18 & 2.20 & 1.67 \\
\hline & Min. ignition flux, $\dot{q}_{i g, \min }^{\prime \prime}\left[\mathrm{kW} \cdot \mathrm{m}^{-2}\right]$ & 13.75 & 10 & 11.25 \\
\hline & Heat transfer coefficient, $h\left[\mathrm{~kW} \cdot \mathrm{m}^{-2} . \mathrm{K}\right]$ & 0.039 & 0.038 & 0.037 \\
\hline & Ignition temperature, $T_{i g}\left[{ }^{\circ} \mathrm{C}\right]$ & 352 & 282 & 307 \\
\hline
\end{tabular}

Table 2. Ignition properties for plain manufactured boards.

\section{Melteca Faced Manufactured Boards}

Melteca consists of melamine facing on a substrate and two brands of Melteca faced board were tested where one used an MDF substrate and the other used particle board. The manufacturer of each board was different so some variation in the performance might be expected due to the differences in the facing material. The exact specification of the particle board substrate was 
unknown but since it was manufactured in New Zealand and had approximately the same density as the Superflake product it was likely to be Radiata Pine and have a similar adhesive. Only the Melteca faced MDF sheet was tested in the LIFT, due to the limited amount of material available.

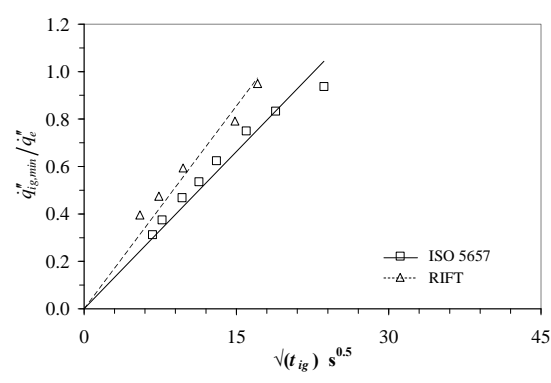

(a)

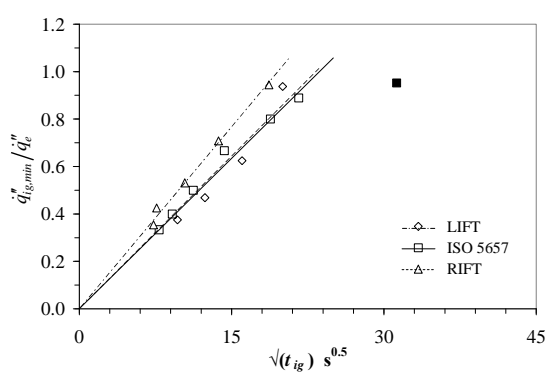

(b)

Figure 6. Determination of ignition parameter for Melteca faced boards: (a) particle board substrate; (b) medium density fibreboard substrate. Data excluded from determination of ignition parameter are shown as solid symbols.

The addition of the melamine facing affected the ignition characteristics of the samples. The facing board bubbled and charred however it did not ignite easily. Charring of the facing occurred at lower flux levels than the underlying material thus insulating the substrate. The substrate pyrolised and as the surface bubbles split, the pyrolised gases escaped and could then ignite. As a result, at low flux levels the ignition time became erratic. The insulating property of the facing material is apparent when comparing the ignition flux to that of the bare substrate material. These charring and ignition mechanisms meant that these materials did not conform to the "well behaved" assumption made in Quintiere et al's ignition theory formulation. The determination of critical heat flux and ignition parameter for Melteca faced boards are shown in Figure 5 and Figure 6 respectively and the derived ignition properties in Table 3. 


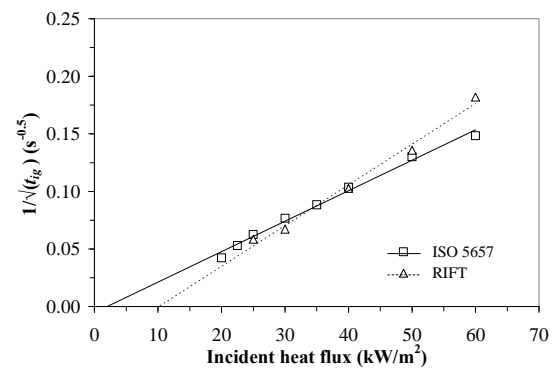

(a)

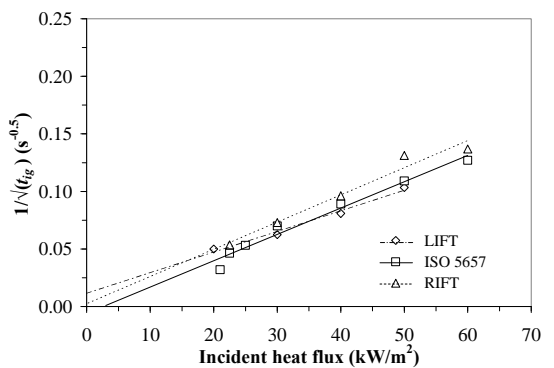

(b)

Figure 5. Determination of critical heat flux for Melteca faced boards: (a) particle board substrate; (b) medium density fibreboard substrate.

\begin{tabular}{|c|c|c|c|c|}
\hline Product & Property & LIFT & ISO 5657 & RIFT \\
\hline \multirow{7}{*}{ 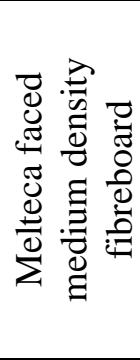 } & Ignition parameter, $b\left[\mathrm{~s}^{0.5}\right]$ & 0.042 & 0.043 & 0.051 \\
\hline & Preheat time, $t^{*}[\mathrm{~s}]$ & 560 & 542 & 382 \\
\hline & Critical ignition flux, $\dot{q}_{c r i t}^{\prime \prime}\left[\mathrm{kW} \cdot \mathrm{m}^{-2}\right]$ & -6.4 & 2.6 & 1.1 \\
\hline & Thermal inertia, $k \rho c\left[\mathrm{~kJ}^{2} \cdot \mathrm{m}^{-4} \cdot \mathrm{K}^{-2} \cdot \mathrm{s}^{-1}\right]$ & 1.48 & 1.47 & 1.07 \\
\hline & Min. ignition flux, $\dot{q}_{i g, \min }^{\prime \prime}\left[\mathrm{kW} \cdot \mathrm{m}^{-2}\right]$ & 18.75 & 20 & 21.25 \\
\hline & Heat transfer coefficient, $h\left[\mathrm{~kW} \cdot \mathrm{m}^{-2} . \mathrm{K}\right]$ & 0.045 & 0.046 & 0.047 \\
\hline & Ignition temperature, $T_{i q}\left[{ }^{\circ} \mathrm{C}\right]$ & 440 & 425 & 454 \\
\hline \multirow{7}{*}{ 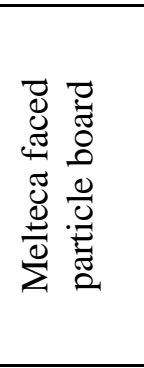 } & Ignition parameter, $b\left[\mathrm{~s}^{0.5}\right]$ & \multirow{7}{*}{ 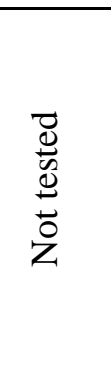 } & 0.044 & 0.057 \\
\hline & Preheat time, $t^{*}[\mathrm{~s}]$ & & 512 & 308 \\
\hline & Critical ignition flux, $\dot{q}_{c r i t}^{\prime \prime}\left[\mathrm{kW} \cdot \mathrm{m}^{-2}\right]$ & & 2.0 & 10.1 \\
\hline & Thermal inertia, $k \rho c\left[\mathrm{~kJ}^{2} \cdot \mathrm{m}^{-4} \cdot \mathrm{K}^{-2} \cdot \mathrm{s}^{-1}\right]$ & & 1.27 & 0.97 \\
\hline & Min. ignition flux, $\dot{q}_{i g, \min }^{\prime \prime}\left[\mathrm{kW} \cdot \mathrm{m}^{-2}\right]$ & & 18.75 & 23.75 \\
\hline & Heat transfer coefficient, $h\left[\mathrm{~kW} \cdot \mathrm{m}^{-2} . \mathrm{K}\right]$ & & 0.044 & 0.050 \\
\hline & Ignition temperature, $T_{i g}\left[{ }^{\circ} \mathrm{C}\right]$ & & 425 & 478 \\
\hline
\end{tabular}

Table 3. Ignition properties for Melteca faced boards.

\section{Natural Timbers}

Radiata Pine is a native of California and it forms the major basis of New Zealand silviculture. Rimu is a native New Zealand timber, although other members of the same family are found through the Pacific Rim. New Zealand Beech belongs to the family of southern Beech trees native to the southern hemisphere. The natural timbers showed greater variation between tests than for manufactured boards because of the deviations in the material due to grain, knots or other features in the timber. Radiata Pine gave similar results in the ISO 5657 apparatus and RIFT and the material still ignited after the 20 min limiting ignition period in the LIFT. During the course of the test, the material noticeably charred over the long test intervals, with some 
surface cracking. Localised surface glowing hot spots were observed over an area of around 2 $\mathrm{cm}$ across. Macrocarpa was also found to ignite at times greater than $20 \mathrm{~min}$ in the LIFT and the ISO 5657 apparatus. Rimu charred less than the softer woods such as Radiata Pine, but the samples tended to bow during the low heat flux tests although this did not appear to have had a significant effect on the results.

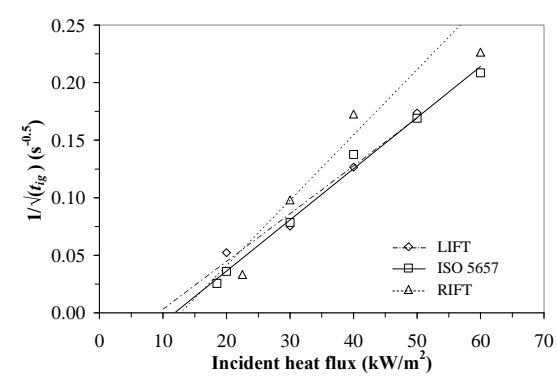

(a)

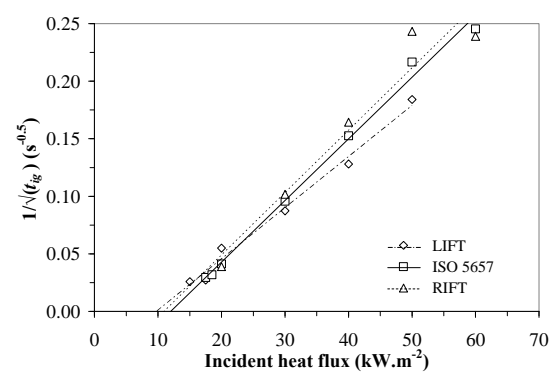

(c)

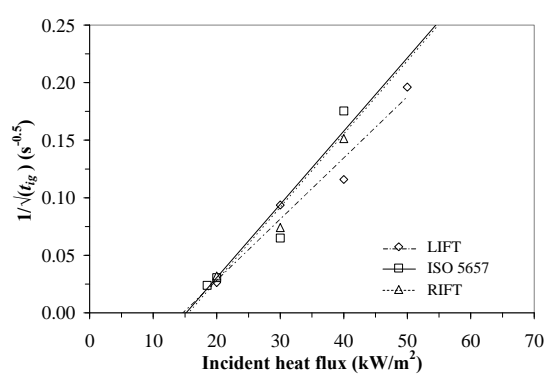

(b)

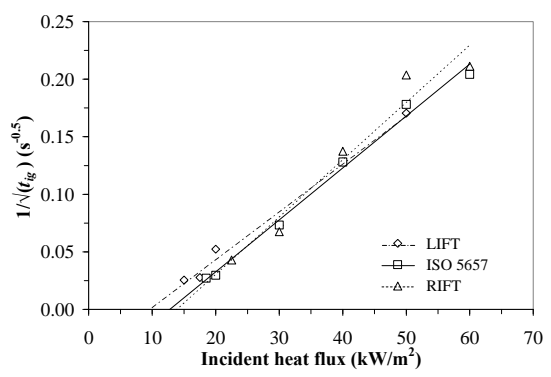

(d)

Figure 7. Determination of critical ignition heat flux for natural timbers: (a) Beech; (b) Macrocarpa; (c) Radiata Pine; (d) Rimu.

The determination of critical ignition heat flux and ignition parameter are shown in Figure 7 and Figure 8. While the ignition parameter results for Beech in the ISO 5657 apparatus and LIFT tests were similar at $0.050 \mathrm{~s}^{0.5}$ and $0.053 \mathrm{~s}^{0.5}$ respectively, the RIFT showed a wide variation, due to the higher minimum ignition flux and shorter times to ignition than produced by the other methods. Figure 8c for Radiata Pine shows that the three different methods gave similar values for the preheating time by eliminating the values for $\left(\dot{q}_{i g, m i n}^{\prime \prime} / \dot{q}_{e}^{\prime \prime}\right)<0.8$ for determining the data fit. The fit of the ignition parameter for Rimu (Figure 8d) also required some data reduction and the results for the RIFT ignition tests have significantly worse fit than those of the other two methods. Table 4 gives a summary of ignition properties obtained for the three test methods for the natural timbers. 


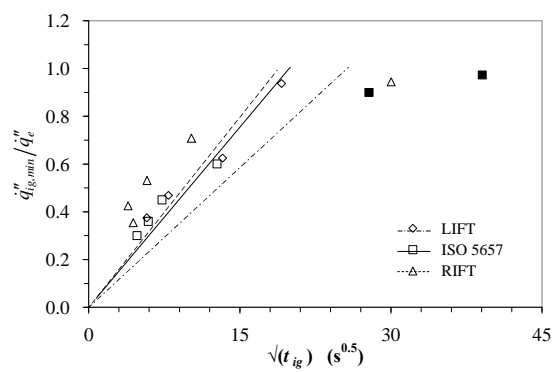

(a)

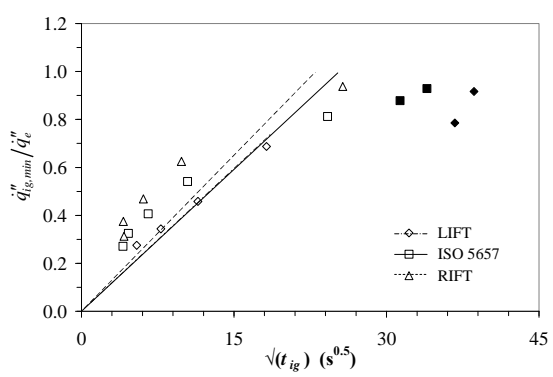

(c)

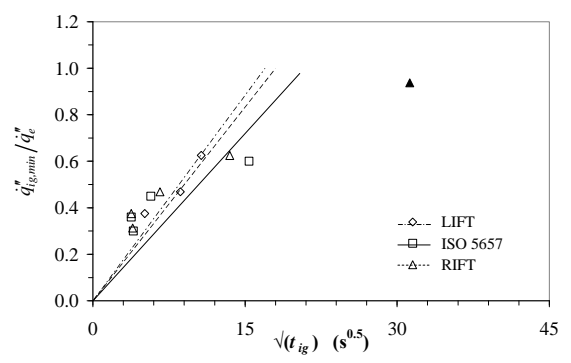

(b)

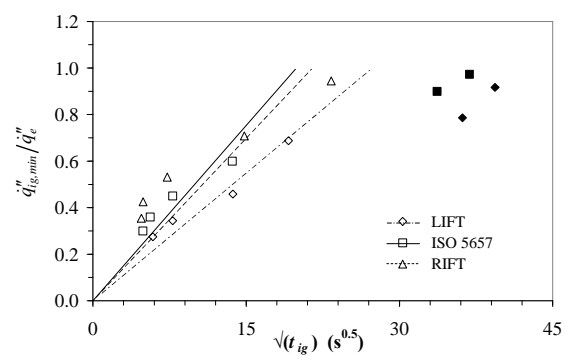

(d)

Figure 8. Determination of ignition parameter for natural timbers: (a) Beech; (b) Macrocarpa;

(c) Radiata Pine; (d) Rimu. Data excluded from determination of ignition parameter are shown as solid symbols.

\section{Application of LIFT, ISO 5657 and RIFT Results}

Babrauskas [16] summarises the availability of ignition data however nominally identical materials can give different results depending on the testing apparatus, procedure and correlations or ignition theory used. In this study the ISO 5657 apparatus gives a consistently lower value for $\dot{q}_{i g, \min }^{\prime \prime}$ than the LIFT whereas the RIFT is generally greater than or equal to the LIFT values (Figure 2) with the exception of hardboard. It has been reported elsewhere [16] that ISO 5657 apparatus and conventional horizontally-oriented cone calorimeter ignition tests give similar results for the minimum ignition flux. Furthermore, Dietenberger [23] found that the minimum ignition flux for Redwood was $4 \mathrm{~kW} \cdot \mathrm{m}^{-2}$ greater in the LIFT when compared to the cone calorimeter in the horizontal position similarly Drysdale [27] found that $\dot{q}_{\dot{q} g \text {,min }}^{\prime \prime}$ is consistently higher in the LIFT when compared to other tests. It appears that the results from this work qualitatively match these previous findings given that the LIFT results are consistently greater than or equal to the minimum ignition heat fluxes obtained in the ISO 5657 apparatus. 


\begin{tabular}{|c|c|c|c|c|}
\hline Product & Property & LIFT & ISO 5657 & RIFT \\
\hline \multirow{7}{*}{ 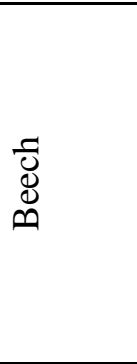 } & Ignition parameter, $b\left[\mathrm{~s}^{0.5}\right]$ & 0.050 & 0.053 & 0.039 \\
\hline & Preheat time, $t^{*}[\mathrm{~s}]$ & 395 & 355 & 657 \\
\hline & Critical ignition flux, $\dot{q}_{c r i t}^{\prime \prime}\left[\mathrm{kW} \cdot \mathrm{m}^{-2}\right]$ & 9.2 & 11.8 & 12.8 \\
\hline & Thermal inertia, $k \rho c\left[\mathrm{~kJ}^{2} \cdot \mathrm{m}^{-4} \cdot \mathrm{K}^{-2} \cdot \mathrm{s}^{-1}\right]$ & 0.98 & 0.85 & 2.01 \\
\hline & Min. ignition flux, $\dot{q}_{i g, \min }^{\prime \prime}\left[\mathrm{kW} \cdot \mathrm{m}^{-2}\right]$ & 18.75 & 18.0 & 21.25 \\
\hline & Heat transfer coefficient, $h\left[\mathrm{~kW} \cdot \mathrm{m}^{-2} . \mathrm{K}\right]$ & 0.044 & 0.043 & 0.049 \\
\hline & Ignition temperature, $T_{i g}\left[{ }^{\circ} \mathrm{C}\right]$ & 425 & 415 & 454 \\
\hline \multirow{7}{*}{ 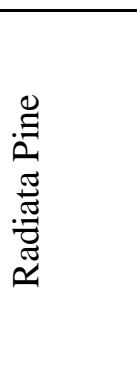 } & Ignition parameter, $b\left[\mathrm{~s}^{0.5}\right]$ & 0.040 & 0.039 & 0.043 \\
\hline & Preheat time, $t^{*}[\mathrm{~s}]$ & 635 & 643 & 531 \\
\hline & Critical ignition flux, $\dot{q}_{\text {crit }}^{\prime \prime}\left[\mathrm{kW} \cdot \mathrm{m}^{-2}\right]$ & 9.7 & 12.0 & 10.9 \\
\hline & Thermal inertia, $k \rho c\left[\mathrm{~kJ}^{2} \cdot \mathrm{m}^{-4} \cdot \mathrm{K}^{-2} \cdot \mathrm{s}^{-1}\right]$ & 1.37 & 1.54 & 1.45 \\
\hline & Min. ignition flux, $\dot{q}_{i g, \min }^{\prime \prime}\left[\mathrm{kW} \cdot \mathrm{m}^{-2}\right]$ & 13.75 & 16.25 & 18.75 \\
\hline & Heat transfer coefficient, $h\left[\mathrm{~kW} \cdot \mathrm{m}^{-2} . \mathrm{K}\right]$ & 0.041 & 0.043 & 0.046 \\
\hline & Ignition temperature, $T_{i g}\left[{ }^{\circ} \mathrm{C}\right]$ & 352 & 391 & 425 \\
\hline \multirow{7}{*}{ 尔 } & Ignition parameter, $b\left[\mathrm{~s}^{0.5}\right]$ & 0.037 & 0.050 & 0.047 \\
\hline & Preheat time, $t^{*}[\mathrm{~s}]$ & 716 & 397 & 462 \\
\hline & Critical ignition flux, $\dot{q}_{c r i t}^{\prime \prime}\left[\mathrm{kW} \cdot \mathrm{m}^{-2}\right]$ & 9.6 & 12.8 & 13.9 \\
\hline & Thermal inertia, $k \rho c\left[\mathrm{~kJ}^{2} \cdot \mathrm{m}^{-4} \cdot \mathrm{K}^{-2} \cdot \mathrm{s}^{-1}\right]$ & 1.54 & 1.03 & 1.41 \\
\hline & Min. ignition flux, $\dot{q}_{i g, \min }^{\prime \prime}\left[\mathrm{kW} \cdot \mathrm{m}^{-2}\right]$ & 13.75 & 18.0 & 21.25 \\
\hline & Heat transfer coefficient, $h\left[\mathrm{~kW} \cdot \mathrm{m}^{-2} . \mathrm{K}\right]$ & 0.041 & 0.045 & 0.049 \\
\hline & Ignition temperature, $T_{i g}\left[{ }^{\circ} \mathrm{C}\right]$ & 352 & 415 & 454 \\
\hline \multirow{7}{*}{ 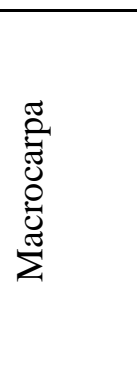 } & Ignition parameter, $b\left[\mathrm{~s}^{0.5}\right]$ & 0.059 & 0.048 & 0.056 \\
\hline & Preheat time, $t^{*}[\mathrm{~s}]$ & 288 & 436 & 325 \\
\hline & Critical ignition flux, $\dot{q}_{c r i t}^{\prime \prime}\left[\mathrm{kW} \cdot \mathrm{m}^{-2}\right]$ & 14.7 & 15.2 & 15.6 \\
\hline & Thermal inertia, $k \rho c\left[\mathrm{~kJ}^{2} \cdot \mathrm{m}^{-4} \cdot \mathrm{K}^{-2} \cdot \mathrm{s}^{-1}\right]$ & 0.78 & 1.13 & 0.89 \\
\hline & Min. ignition flux, $\dot{q}_{i g, \min }^{\prime \prime}\left[\mathrm{kW} \cdot \mathrm{m}^{-2}\right]$ & 18.75 & 18.0 & 18.75 \\
\hline & Heat transfer coefficient, $h\left[\mathrm{~kW} \cdot \mathrm{m}^{-2} . \mathrm{K}\right]$ & 0.046 & 0.045 & 0.046 \\
\hline & Ignition temperature, $T_{i g}\left[{ }^{\circ} \mathrm{C}\right]$ & 425 & 415 & 425 \\
\hline
\end{tabular}

Table 4. Ignition properties for natural timbers. 


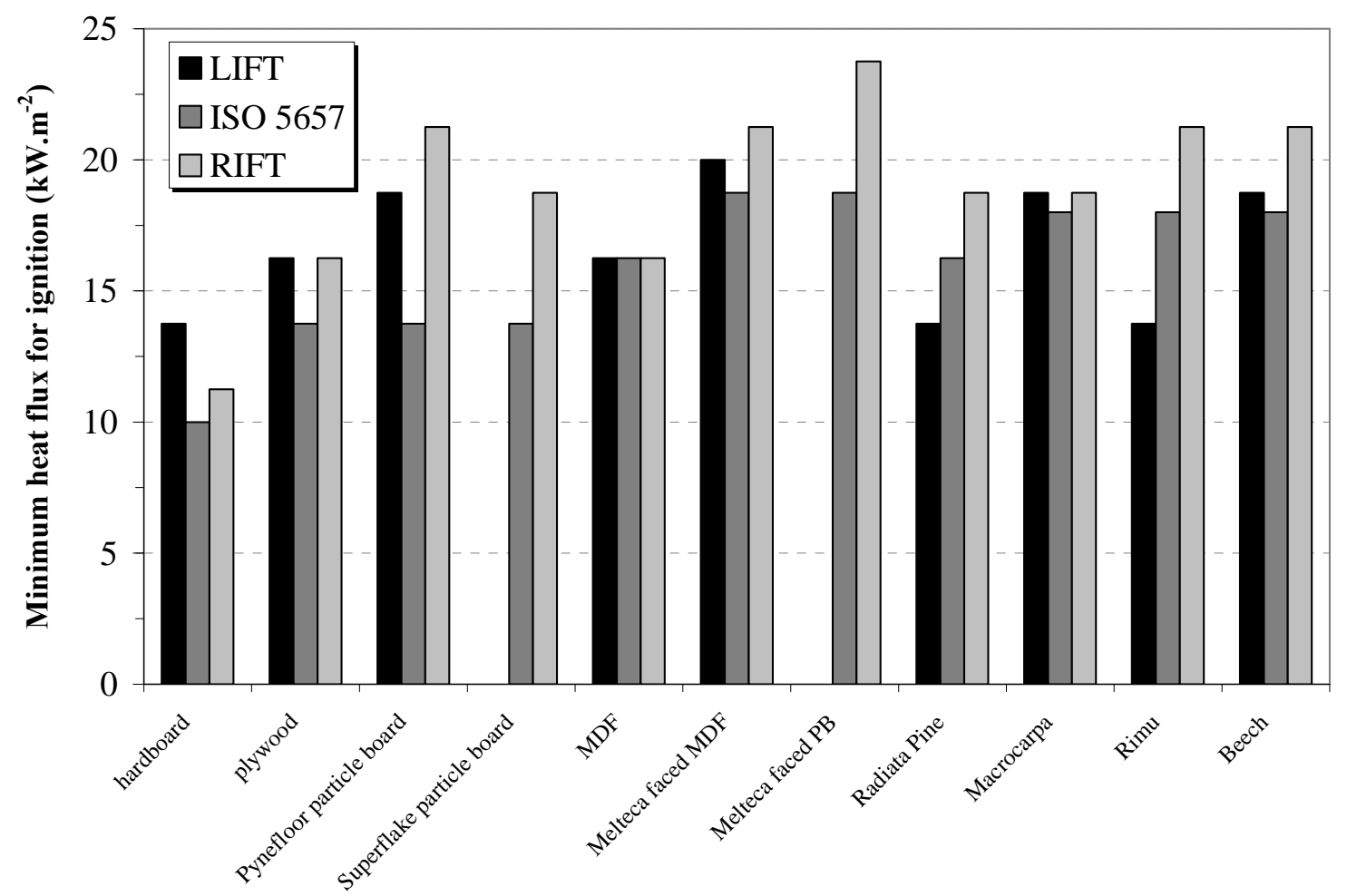

Figure 2. Comparison of minimum ignition heat fluxes from the LIFT, ISO 5657 apparatus and RIFT.

The difference in the results is likely due to the convective heat losses from the surface of the material at ignition. The heat transfer coefficient for horizontal samples in the cone calorimeter is commonly $0.013 \mathrm{~kW} / \mathrm{m}^{2} . \mathrm{K}$ [16] and is similar or less [28] in the ISO 5657 apparatus whereas it is generally higher for vertically oriented samples. The ASTM E 1321-97a standard specifies that the LIFT has a heat transfer coefficient of $0.015 \mathrm{~kW} / \mathrm{m}^{2} . \mathrm{K}$, although Dietenberger [23] found the heat transfer coefficient varied along the sample and was much higher at the hot end of the sample. The effect of the larger sample size in the LIFT compared with the RIFT is expected to be less important since $h_{c} \propto 1 / L^{1 / 4}$ [29] where $L$ is the sample size.

In general the ISO 5657 apparatus produced higher thermal inertia values than the LIFT, and the RIFT shows more variation compared with the other two methods (Figure 3). Data from the LIFT and ISO 5657 apparatus show that the thermal inertia values increase with density, as might be expected, but the data scatter from the RIFT exhibits no useful correlation between thermal inertia with density. Values obtained for Plywood and MDF from the three test methods are very similar, however despite being made from the same base material, there is a significant 
range of values for the thermal inertia of Pynefloor and Superflake particle board and between the results from different test methods on the same material.

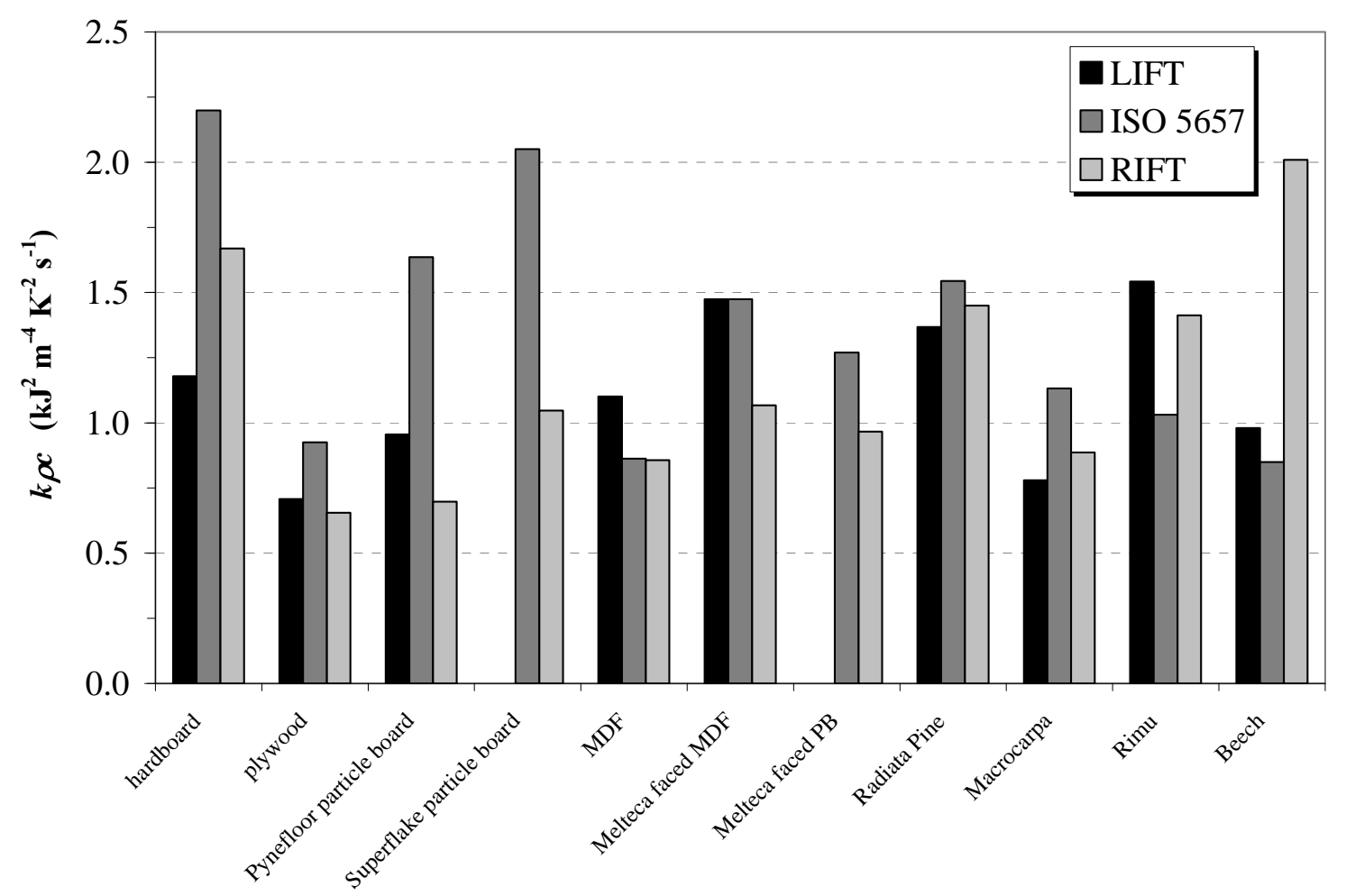

Figure 3. Comparison of derived thermal inertia from the LIFT, ISO 5657 apparatus and RIFT.

For the subsequent flame spread testing conducted by Merryweather [14] the LIFT ignition data was used for the LIFT flame spread tests so as to follow the ASTM E 1321-97 protocol. For the RIFT apparatus flame spread tests the decision was made to focus on the ignition parameters obtained using the conventional ISO 5657 apparatus rather than those obtained from the alternative RIFT arrangement as results from the latter test were found to be less consistent.

\section{CONCLUSION}

An ASTM E 1321 Lateral Ignition and Flame spread Test (LIFT) apparatus and a Reduced scale Ignition and Flame spread Test (RIFT) apparatus to fit the cone calorimeter in the vertical position have been constructed and tested. Due to the limitations imposed by LPG on achieving low flux levels it was necessary to adjust the burner position in the LIFT further away from the sample during the ignition tests so that minimum flux levels at the sample face of $11 \mathrm{~kW} \cdot \mathrm{m}^{-2}$ could be obtained. The results obtained from the three test methods exhibited the expected differences in the minimum ignition flux between horizontally and vertically oriented samples. The thermal inertia values determined from the RIFT were found to be less consistent than those 
obtained from the LIFT and ISO apparatus. The ignition parameter values presented in this paper were sufficient for flame spread tests and a comparison between the standard LIFT and the RIFT addition to the cone calorimeter given by Merryweather [14].

\section{ACKNOWLEDGEMENTS}

The authors would like to thank Grant Dunlop and Bob Smith for their assistance in constructing the various test apparatus. We would also like to acknowledge the New Zealand Fire Service Commission for their support of the Fire Engineering programme at the University of Canterbury.

\section{REFERENCES}

1. Cleary T, Quintiere J. (1991). Framework for utilizing fire property tests - NISTIR 4619. Proc. $3^{\text {rd }}$ International Symposium on Fire Safety Science. July 8-12, 1991, Edinburgh, Scotland, Publ. Elsevier Applied Science, New York, Editors Cox, G.; Langford, B. pp 647656.

2. ASTM E 1321-97a. (1997). Standard test method for determining material ignition and flame spread properties. ASTM International, West Conshohocken, PA, USA.

3. ASTM E 1354. (2004). Standard test method for heat and visible smoke release rates for materials using an oxygen consumption calorimeter. ASTM International, West Conshohocken, PA, USA.

4. Jianmin Q. (1990). Prediction of flame spread test results using the test data from the cone calorimeter. SP Report 1990:38. Fire Technology, Boras, Sweden.

5. Goransson U. (1990). Using the cone calorimeter to predict flame spread. Nordtest project 882-90. SP Report AR1991:32. Fire Technology, Boras, Sweden.

6. Persson B. (1993). On the prediction of lateral flame spread based on cone calorimeter data. SP Report 1993:28. Fire Technology, Boras, Sweden.

7. Azhakesan A. Shields, T J, Silcock G. (1998). Ignition and opposed flow flame spread using a reduced scale attachment to the cone calorimeter. Fire Technology, Vol. 34, No. 2, pp.99115.

8. Azhakesan A, Shields T J, Silcock G. (1998). Combustibility parameters for enclosure lining materials obtained during surface flame spread using reduced scale ignition and flame spread technique. Fire Technology, Vol. 34, No. 3, pp.197-226.

9. Quintiere J. (1981). A simplified theory for generalizing results from a radiant panel rate of flame spread apparatus. Fire and Materials, Vol 5, No. 2, pp.52-60.

10. Quintiere J, Harkleroad M, Walton D. (1983). Measurement of flame spread properties. Combustion Science and Technology, Vol 32. pp. 67-89. 
11. Quintiere J, Harkleroad M. (1984). New concepts for measuring flame spread properties. NBSIR 84-2943, National Institute of Standards and Technology, Gathersburg, MD, USA.

12. Pease T. (2001). A study of surface flame spread using a modified cone calorimeter. Undergraduate final year project. Department of Chemical Engineering, University of Newcastle, Australia.

13. Huynh C K. (2003). Flame spread measurements of New Zealand timber using a modified cone calorimeter. Masters of Engineering in Fire Engineering thesis, University of Canterbury, Christchurch, New Zealand.

14. Merryweather G. (2006). Comparison of flame spread measurements using the ASTM E 1321 LIFT and a reduced scale adaptation of the cone calorimeter apparatus. Masters of Engineering in Fire Engineering thesis, University of Canterbury, New Zealand.

15. Babrauskas V. (2001). Ignition of wood: A review of the state of the art. Proc. 9th Int'l Interflam Conference, September 17-19, 2001, Edinburgh, Scotland. Interscience Communications Ltd., London, England, pp. 71-88.

16. Babrauskas V. (2003). Ignition handbook. Fire Science Publishers, Fire Science and Technology, Inc, Issaquah, WA, USA.

17. Dietenberger M A. (2004). Ignitability of materials in transitional heating regimes. Proc, $5^{\text {th }}$ Int’l Conference on Wood \& Fire Safety, Štrbské Pleso, Slovak Republic, April 18-22.

18. Cleary T. (1992). Flammability characterization with the LIFT apparatus and the cone calorimeter. Technical and Marketing Issues Impacting the Fire Safety of Building and Construction and Home Furnishings Applications, 1992. Orlando, FL. Technomic Publishing Co., Lancaster, PA, pp. 99-115.

19. Babrauskas V, Wetterlund I.(1999). Comparative data from LIFT and cone calorimeter tests on 6 products, including flame flux measurements. SP report 1999:14, SP Swedish National Testing and Research Institute, Sweden.

20. ASTM E 1317-97a. (1997). Standard test method for flammability of marine surface finishes. American Society of Testing and Materials, ASTM International, West Conshohocken, PA, USA.

21. Grand A F, Mehrafza M. (2001). Evaluation of the effectiveness of fire resistant durable agents on residential siding using an ICAL based testing protocol. Proc. Fire and Materials 2001, $7^{\text {th }}$ Int'l Conference. Interscience Communications Ltd. Jan 22-24, 2001, San Antonio, USA. pp. 241-248.

22. Pauner M. (2003). Nordic round robin and investigation on IMO Resolution A. 653 (16) TR 529. Nordtest, Finland.

23. Dietenberger M. (1996). Ignitability analysis using the cone calorimeter and LIFT apparatus. Proc. Int'l Conference on Fire Safety: July 22-26, 1996, Columbus, OH. Vol. 22. pp. 189-197. 
24. Shields T J, Silcock G, Murray J. (1993). The effects of geometry and ignition mode on ignition times obtained using a cone calorimeter and ISO ignitability apparatus. Fire and Materials, 17 (1), pp.25-32.

25. de Ris J L, Khan M M. (2000). A sample holder for determining material properties. Fire and Materials, Vol. 20, Issue 5, pp. 219-226.

26. Ngu M. (2002). Ignition of New Zealand timber. Masters of Engineering in Fire Engineering thesis, University of Canterbury, Christchurch, New Zealand.

27. Drysdale D D. (1999). An introduction to fire dynamics, $2^{\text {nd }}$ ed., Wiley, Chichester, England.

28. Chen F. (2001). Radiant ignition of New Zealand upholstered furniture composites. Fire Engineering Research Report 2001/2, University of Canterbury.

29. Long R T jr, Torero J L, Quintiere J G, Fernandez-Pello A C. (2000) .Scale and transport considerations on piloted ignition of PMMA, Fire Safety Science - Proc. $6^{\text {th }}$ Intl. Symp. Intl. Assoc. for Fire Safety Science, pp. 567-578. 